May 13 to 16 there fell $106 \mathrm{~mm}$. rain, about one-ninth of our total yearly quantity; on the $13^{\text {th }}, 26 \mathrm{~mm}$.; $14^{\text {th }}, 27^{\circ} 6$; $15^{\text {th }}$, 22.4 ; 16 th, 30 . These heavy rains were undoubtedly due to the northern storm, although they came two days later.

Caracas, June 29

A. ERNST

\section{The Indivisibility of Certain Whole Numbers}

ANother exception has been found to Fermat's assertion regarding the indivisibility of whole numbers of the form $2^{2^{2}}+I$ (see several notices in NATURE, vols, xviii. and xix.). The matter now stands as follows:-

$$
\begin{array}{ccc}
2^{2^{5}}+I & \text { divisible by } & 5 \cdot 2^{7}+1 \text { (Euler) } \\
2^{2^{6}}+\mathrm{I} & , & \text { I0 } 71 \cdot 2^{8}+\mathrm{I} \text { (Landry) } \\
2^{2^{12}}+\mathrm{I} & , & 7 \cdot 2^{14}+\mathrm{I} \text { (Pervouchine) } \\
2^{2^{23}}+\mathrm{I} & , & 5 \cdot 2^{25}+\mathrm{I} \text { (Pervouchine) } \\
2^{2^{36}}+\mathrm{I} & , & 5 \cdot 2^{39}+\mathrm{I} \text { (Seelhoff). }
\end{array}
$$

M.

\section{A Quadruped Duck}

IT may interest some readers of NATURE to hear that there is at present living in Bardsea a duck which has four feet. The two abnormal feet, which are webbed like the others, and of the same shape and size, spring from one leg, which is about the same length as the normal legs, but rather thicker. This leg grows from a point just beneath the tail. Its bone does not seem to be directly connected with the other bones of the bird, as it can be freely moved in any direction. This duck is more than a month old, and is healthy. EDwARD GEOGHEGAN

Bardsea, August 3

\section{PHYSIOLOGICAL SELECTION: AN ADDI- TIONAL SUGGESTION ON THE OKIGIN OF SPECIES 1}$$
\text { I. }
$$

THERE are three cardinal difficulties in the way of natural selection, considered as a theory of the origin of species.

(I) The difference between species and varieties in respect of mutual fertility. Many of our domesticated varieties differ from one another to an extent greater than that which distinguishes many natural species: yet they continue perfectly fertile inter se, while the natural species are nearly always more or less sterile. The difficulty is not met by pointing to the fact that sterility between natural species is neither absolutely constant nor constantly absolute ; for the question still remains, Why are the modifications of organic types supposed to have been produced by natural selection, so generally attended with some more or less pronounced degree of mutual sterility, when even greater modifications of such types produced by artificial selection so generally continue mutually fertile? That this question does not admit of any answer by the theory of natural selection Mr. Darwin himself acknowledges, and therefore suggests a wholly independent hypothesis by which to explain the fact. This hypothesis is, that varieties occurring under nature "will have been exposed during long periods of time to more uniform conditions than have domesticated varieties, and this may well make a wide difference in the result." Now, whatever we may think of this hypothesis, it is certainly quite distinct from the theory of natural selection; and, therefore, any one who adopts the supplementary hypothesis is, so far, confessing the inadequacy of that theory, considered as a theory of the origin of species. For my own part, I deem the hypothesis wholly insufficient to meet the facts. When we remember the incalculable number of species, living and extinct, we immediately feel the necessity for

I Abstract of a Paper read before the Linnean Society on May 6, by George J. Romanes, M.A., LL.D., F.R.S. \&c. some much more general explanation of their existence than is furnished by supposing that their mutual sterility, which constitutes their most general or constant distinction as species, was in every case due to some incidental effect produced on the generative system by uniform conditions of life. To say nothing of the antecedent improbability that in all these millions and millions of cases the reproductive system should happen to have been affected in this peculiar way by the merely negative condition of uniformity, there remains what seems to me the overwhelming consideration that, at the time when a variety is first forming, the condition of prolonged exposure must necessarily be absent as regards that variety: yet this is just the time when we must suppose that the infertility with its parent form arose. Because, if not, the incipient variety would have been reabsorbed into its parent form by intercrossing.

(2) For the swamping effects of free intercrossing upon an individual variation constitutes the next, and perhaps the most formidable, difficulty with which the theory of natural selection is beset. The only answer which Mr. Darwin has to make in this case is that a number of individuals inhabiting the same area may vary in the same way at the same time. Of course, if this assumption were granted, there would be an end of the present difficulty; for if a sufficient number of individuals were thus similarly and simultaneously modified, there need no longer be any danger of the variety being swamped by intercrossing. But the force of the difficulty consists in the very fact of this assumption being required to meet it. The theory of natural selection trusts to the chapter of accidents in the matter of variation; and in this chapter we read of no reasons why the same beneficial variation should arise in a number of individuals simultaneously. Moreover, if it does so, the fact of its doing so cannot be attributed to natural selection, which thus again fails as a theory of the origin of species. Lastly, as will immediately be shown, a very large proportion, if not the majority, of features which serve to distinguish species. from species, are features presenting no utilitarian significance; and, therefore, even if it be conceded that they each arose in a number of individuals simultaneously, their reabsorption by intercrossing could not have been in any degree hindered by natural selection.

(3) The difficulty just alluded to of the inutility to species of so large a proportion of specific distinctions, is one which Mr. Darwin frankly acknowledges in the later editions of his works. In other words, he allows that a large proportion of these distinctions resemble the more general distinction of sterility in not admitting of any explanation by the theory of natural selection. They consist of small and trivial differences of form and colour, or of meaningless details of structure, which, being of no service to the plants or animals presenting them, cannot have arisen through the agency of natural selection. If it be suggested that all such distinctions are of disguised utility, the answer is that to offer this suggestion is to reason in a circle. For the only evidence we have of natural selection as an operating cause in any case is derived from the utility of the observed results: therefore, in cases where utility is apparently absent, we may not assume that it must be present only because, if it were not present, the results must be due to some cause other than natural selection. Observe, the case would be different if the great majority of specific distinctionslike the great majority of higher distinctions-were of obvious utilitarian significance; for in this case we might reasonably set down the exceptions as proof of the rule, or hold that they appear to be exceptions only on account of our ignorance. But it is certainly too large a demand on our faith in natural selection to appeal to the argument from ignorance when the facts require that the appeal should be made over so very large a proportion of instances. But it is needless further to insist upon this 
point, since, as I have already observed, its force has been fully recognised by Mr. Darwin and his followers. Here again, therefore. the theory of natural selection fails as a theory of the origin of species. ${ }^{1}$

In view of these three grave disabilities under which the theory of natural selection lies, I feel entitled to affirm that the theory has been misnamed. Natural selection is not, properly speaking, a theory of the origin of species: it is a theory of the origin-or rather of the cumulative development-of adaptations, whether these be morphological, physiological, or psychological ; and whether they occur in species only, or likewise in genera, families, orders, or classes. These two things are very far from being the same; for, on the one hand, in an enormously preponderating number of instances, adaptive structures are common to numerous species, while, on the other hand, the features which serve to distinguish species from species are, as we have just seen, by no means invariably -or even generally - of any adaptive character. If once it is thus clearly perceived that the theory of natural selection is not a theory of the origin of species, but a theory of the development of adaptive structures-whether these happen to be distinctive of species or of higher taxonomical divisions-if once this is clearly perceived, the theory is released from all the difficulties which we have been considering. For these difficulties have beset the theory only because it has been made to pose as a theory of the origin of species, whereas in point of fact it is nothing of the kind. In so far as natural selection has had anything to do with the genesis of species, its operation has been, so to speak, incidental: it has only helped in the work of originating species in so far as some among the adaptive variations which it has preserved happen to have constituted differences of merely specific value. Many other such differences there are with which natural selection has had nothing to do-particularly the most universal of all such differences, or that of mutual sterility -while, on the other hand, by far the larger number of adaptations which have been the work of natural selection are now the common property of genera, families, orders, or classes. Let it, therefore, be clearly understood that it is the office of natural selection to evolve adaptations: not necessarily, or even generally, to originate species.

Let it also be clearly understood that in thus seeking to place the theory of natural selection on its true logical footing, I am in no wise detracting from the importance of that theory. On the contrary, I am but seeking to release the theory from the difficulties with which it has been hitherto illegitimately surrounded.

Enough has now been said to justify the view that there must be some cause or causes other than natural selection operating in the evolution of species. And this is no more than Mr. Darwin himself has expressly and repeatedly stated to have been his own view of the matter; nor am I aware that any of his followers have thought otherwise. Hitherto the only additional causes of any importance that have been assigned are use and disuse, sexual selection, correlated variability, and yet another principle which I believe to have been of much more importance than any of these. Yet it has attracted so little attention as scarcely ever to be noticed by writers on evolution, and never even to have received a name. For the sake of convenience, therefore, I will call this principle the Prevention of Intercrossing with Parent Forms, or the Evolution of Species by Independent Variation.

First let us consider how enormous must be the number of variations presented by every generation of every

I. Of the three cardinal objections to the theory of natural selection thus briefly stated, Mr. Darwin himself appears to have attributed most importance to the first, seeing that its consideration occupies so large a portion of his writings. The objection from intercrossing, on the other hand (which was first rendered with much force and clearness by the late Prof. Fleeming Jenkin of Ediuburgh, in an an nymous article, North British Reviezw, r867), is the only difficulty in the way of his theory which Mr. Darwin can fairly be said not to have sufficiently treated. The objection from inutility was first prominently raised by Bronn. It was afterwards developed by Nägeli, Broca, Mivart, and many other writers. species. According to the Darwinian theory it is for the most part only those variations which happen to have been useful that have been preserved: yet, even as thus limited, the principle of variability is held able to furnish sufficient material out of which to construct the whole adaptive morphology of nature. How immense, therefore, must be the number of unuseful variations! Yet these are all for the most part still-born, or allowed to die out imme. diately by intercrossing. Should such intercrossing be prevented, however, there is no reason why unuseful variations should not be perpetuated by heredity quite as well as useful ones when under the nursing influence of natural selection - as, indeed, we see to be the case in our domesticated productions. Consequently, if from any reason a section of a species is prevented from intercrossing with the rest of its species, we might expect that new varieties (for the most part of a trivial and unuseful kind) should arise within that section, and that in time these varieties should pass into new species. And this is exactly what we do find. Oceanic islands, for example, are well known to be extraordinarily rich in peculiar species; and this can best be explained by considering that a complete separation of the fauna and flora of such an island permits them to develop independent histories of their own, without interference by intercrossing with their originally parent forms. We see the same principle exemplified by the influence of geographical barriers of any kind, and also by the consequences of migration. When a species begins to disperse in different directions from its original home, those members of it which constitute the vanguard of each advancing army are much more likely to perpetuate any individual variations that may arise among them than are the me nbers which still occupy the original home. For not only is the population much less dense on the outskirts of the area occupied by the advanced guard ; but beyond these outskirts there lies a wholly unoccupied territory, upon which the new variety may gain a footing during the progress of its further migration. Thus, instead of being met on all sides by the swamping effects of intercrossing with its parent form, the new variety is now free to perpetuate itself with comparatively little ris's of any such immediate extinction. And, in the result, wherever we meet with a chain of nearly allied specific forms so distributed as to be suggestive of migration with continuous modification, the points of specific difference are trivial or non-utilitarian in character. Clearly this general fact is in itself enough to prove that, given an absence of overwhelming intercrossing, independent variability may be trusted to evolve new species. The evidence which I have collected, and am collecting, of the general fact in question, must be left to constitute the subject of a future paper. ${ }^{1}$

Were it not for the very general occurrence of some degree of sterility between even closely allied species, and were it not also for the fact that closely allied species are not always separated from one another by geographical barriers, one might reasonably be disposed to attribute all cases of species-formation by independent variability to the prevention of intercrossing by geographical barriers, or by migration. But it is evident that these two facts can no more be explained by the influence of geographical barriers or by migration than they can by the influence of natural selection. The object of the present paper is to suggest an additional factor in the formation of specific types by independent variability, and one which appears to me fully competent to explain both the general facts just mentioned.

I So far as I am aware, the first writer who insisted on the importance of the prevention of intercrossing in the evolution of species, b th by isolation and migration, was Moritz Wagner. Since then Wallace, Weismann, and others have recognised this fact $ว$ r. The most recent contribution to the subject is an admirable collection of facts published by Mr, Charles Dixon in a work entitled, "Evolution without Natural Selection," which was recently reviewed in these columns. But I cannot find that any of these writers allude to the principle which it is the object of the present paper to enunciate, and which is explained in the succeeding paragraphs. 
Of all parts of those variable objects which we call organisms, the most variable is the reproductive system ; and the variations may be either in the direction of increased or of diminished fertility. Having, regard, therefore, to all the delicate, complex, and for the most part hidden conditions which determine this double kind of variation within the limits of the reproductive system, there can be no difficulty in granting that variations in the way of greater or less sterility must frequently occur both in plants and animals in a state of nature. Probably, indeed, if we had the means of observing this point, we should find that there is no one variation more common. But, of course, whenever it arises - whether as a result of changed conditions of life, or, as we say, spontaneouslyit immediately becomes extinguished, seeing that the individuals which it affects are less able (if able at all) to propagate the variation. But now, if the variation should be such that, while showing some degree of sterility with the parent form, it continues to be perfectly fertile within the limits of the varietal form, in this case the variation would neither be swamped by intercrossing, nor would it die out on account of sterility. On the contrary, this particular variation would be perpetuated with more certainty than any other variation, whether useful or unuseful. An illustration will serve to render this more clear.

Suppose the variation in the reproductive system is such that the season of flowering or of pairing becomes either advanced or retarded. Whether this variation be, as we say, spontaneous, or due to any change of food, climate, habitat, \&c., does not signify. The only point we need here attend to is that some individuals, living on the same geographical area as the rest of their species, have varied in their reproductive systems so that they are perfectly fertile inter se, while absolutely sterile with all other members of their species. By inheritance there would thus arise a variety living on the same geographical area as its parent form, and yet prevented from intercrossing with that form by a barrier quite as effectual as a thousand miles of ocean: the only difference is that the barrier, instead of being geographical, is physiological.

From this illustration I hope it will be obvious that wherever any variation in the highly variable reproductive system occurs, tending to sterility with the parent form without impairing fertility with the varietal formno matter whether this be due, as here supposed, to a slight change in the season of reproductive activity, or to any other cause-there the physiological barrier in question must interpose, with the result of dividing the species into two parts. And it will be further evident that when such a division is effected, the same conditions are furnished to the origination of new species as are furnished to any part of a species when separated from the rest by geographical barriers or by migration. For now the two sections of the species, even though they be living on the same area, are free to develop distinct histories without mutual intercrossing, or, as I have phrased it, by independent variation.

To state this suggestion in another form. It enables us to regard many, if not most, natural species as the records of variation in the reproductive systems of ancestors. When accidental variations of a non-useful kind occur in any of the other systems or parts of organisms, they are as a rule, immediately extinguished by intercrossing. But whenever they hapjpen to arise in the reproductive system in the way here suggested, they must inevitably tend to be preserved as new natural varieties, or incipient species. At first the difference would only be in respect of the reproductive system; but eventually, on account of independent variation, other differences would supervene, and the new variety would take rank as a true species.

The principle thus briefly sketched in some respects resembles, and in other respects differs from, the principle of natural selection. or survival of the fittest, as I will show later on. For the sake of convenience, therefore, and in order to preserve analogies with already existing terms, I will call this principle Physiological Selection, or Segregation of the Fit.

Before proceeding to state the evidence of the particular kind of variation on which this principle depends, let it be noted that we are not concerned either with its causes or its degrees. Not with its causes, because in this respect the theory of physiological selection is in just the same position as that of natural selection: it is enough for both that the needful variations are provided, without its being incumbent on either to explain the causes which underlie them. Neither are we concerned with the degrees of sterility which the variation in question may in any particular case supply. For whether the degree of sterility with the parent form be originally great or small, the result of it will in the long run be the same : the only difference will be that in the latter case a greater number of generations would be required in order to separate the varietal from the parent form.

(To be continued.)

\section{TROPICAL FRUITS}

$\mathrm{THE}$ present Colonial and Indian Exhibition has developed interest in tropical fruits to an extent not previously known in England; and whatever may be the individual merits of many of the fruits displayed in the colonial market attached to the Exhibition, no one can deny that they afford proof of numerous undeveloped resources of our colonial possessions in a direction hitherto very much undervalued or entirely overlooked. Sir Joseph Hooker, in one of his journals, has remarked that "most tropical fruits are edible, but few are worth eating." But, after all, the merits of many fruits like those of certain wines are only properly appreciated under a concourse of local circumstances which materially affect our verdict. In the tropics the desire for refreshment and for something cooling and piquant is met by a fruit which, at the moment, completely answers the purpose. Transferred to a cooler climate, the same fruit may be entirely out of place, and indeed may be condemned as valueless. As a case in point, the water of a young cocoa-nut, when clear and fresh, taken from the fruit after a long ride in the sun, is most refreshing and wholesome. The same thing tried in the climate of England, and with fruit imported from the tropics, would be nauseous and wholly unpalatable. Similar remarks would apply to the fruit of the mangosteen, the durian, and many others where it is necessary that the fruit should be eaten when just ripe, and where a long journey affects the quality and impairs the delicacy -both being of an evanescent character.

Again, it is necessary to bear in mind how to use certain tropical fruits in order to appreciate them to the best advantage. Owing to the loose manner in which tropical fruits are termed, apples, plums, pears, peaches, \&c., when they are neitber botanically nor intrinsically anything of the sort, there has arisen considerable confusion respecting them. Again, many tropical fruits are suitable only for salads or curries, and should not appear at the dessert table at all. Others are better when preserved or cooked, and they are then both wholesome and well adapted to the wants of the country. There is no good pear (Pyrus communis, L.), as known in England, grown in the tropics, yet we have the name applied to the Alligator or Avocado pear (Persea gratissima, Gart), the anchovy pear (Grias cauliftora, L.), the prickly pear (Opuntia ficus-indica, Webb), and the wooden pear of Australia (Xylomelum pyriforme, Knight). Again, the English apple, although grown in the hills in the tropics, is practically of little value, but the name is as loosely applied as in the case of the pear, and hence fruits as widely apart as the poles in their botanical classi-

r. Lecture given in the Conference Hall, Colonial Exhibition. Revised by the Author. 